\title{
Research on the Evolution and Key Mechanism of Digital Currency Based on "Block Chain"
}

\author{
Zhaoyi Xu' ${ }^{1, a}$, Yuhao Zeng ${ }^{2, b}$ and Shenfeng Deng ${ }^{3, c}$ \\ ${ }^{1}$ College of Finance and Statistics, Hunan University, Changsha 410011, China \\ ${ }^{2}$ College of Foreign Languages, Xi'an Jiaotong University, Xi'an 710000, China \\ ${ }^{3}$ Finance Department of Hunan Province, Changsha 410015, China \\ axuzhaoyi1995@outlook.com, b1428351991@qq.com, c695506712@qq.com
}

Keywords: digital currency; block chain technology; credit mechanism; risk regulation

\begin{abstract}
Digital currency is a great change in the financial field and the research of digital currency has long been carried out. In the era of fast changing Internet, digital currency has attracted much attention. Moreover, its development and supervision are the core issues. The development of block chain technology has exerted great effect on the digital currency. Based on the block chain technology, this paper analyzes the evolution of digital currency and tries to figure out related reasons. Furthermore, this paper analyzes the mechanism of digital currency from different angles, mainly including the nature, attribute, anchoring and credit creators of digital currency. Under the different conditions of financial innovation efficiency and currency risk, it's necessary to design the idea of the core mechanism of digital currency and analyze the practical operation and development prospect of digital currency. Based on the understanding of the risk of digital currency, it's imperative to put forward effective supervision system and regulatory strategy, so that digital currency can run smoothly and play an active role in the Internet era.
\end{abstract}

\section{Introduction}

In 2016, China's President Xi Jinping put forward the development idea of global digital economy at the G20 summit. In January 2016, the People's Bank of China emphasized on the issue of digital currency. This is the change of the form of currency in the new period and the embodiment of the better money for the social service. In addition to paper money, there are also digital, virtual and other monetary forms. With the development of the Internet and the progress of science and technology, the power of science and technology has also penetrated into the financial field. The development of block chain technology and the practical application in the field of finance and currencies are a great embodiment. Digital currency is no stranger to people, which is different from electronic money and virtual currency. A comparison of electronic money or virtual currency is often adopted in research on digital currency. By reference of its risk analysis and regulatory countermeasures, evolution and imagination of specific forms are made. Through analyzing and summarizing evolution process and law of digital currency, this paper combed the process of digital currency and explored the core mechanism, so as to put forward reasonable regulatory measures for current and future digital currencies.

\section{Evolutionary Process of Digital Currency}

As a new form of currency, digital currency comes from financial innovation. Financial innovation refers to the application of science and technology in the financial sector, including banks, securities and other industries. It can present new patterns and expressions of operation mode, process and product of the financial field via new technology. Moreover, these outcomes will be widely applied in the society, thus accelerating the development of the whole financial field. On the one hand, this 
innovation is manifested as internal innovation, that is, management innovation, organization reconstruction and personnel mobilization within the financial system. These innovations can be utilized for changes of currency. On the other hand, this innovation can be the external and explicit innovation, that is, the distribution and optimization of the digital currency can directly act on the financial market. Financial innovation directly drives the progress of digital currency. Under the background of cloud computing, big data and artificial intelligence, digital currency will have more room to play its role and show its unique value. The development of financial technology is largely based on the development of digital currency in block chain technology. The evolution of the digital currency revolves around the three major issues of the value of money, the issuer and the amount of money, so as to explore the mechanism of digital currency. In different conditions of the efficiency of financial innovation and the risk of currency, the idea of designing the core mechanism of the digital currency and the analysis of the practical operation and development prospect of the digital currency are the needs of the financial development.

\subsection{Evolutionary process of monetary form}

Currency is gradually generated in the process of continuous exchange of human beings. Subsequently, the form of money also changes with the development of commodity economy. Commodity currency is the initial form of currency. The emerging of metal coins and paper money can be an important form in the history of money, which greatly improves the efficiency of money and strengthens the credit of money. After the industrial revolution, information technology has been fully developed. Electronic network equipment has become the mainstream social networking tool and electronic payment has also been widely applied. Electronic currency gradually takes the place of paper currency and plays a leading role in people's lives. Since 2000, the virtual currency has entered people's life. In 2013, the new digital currency based on block chain has been taken seriously. The development of money is accompanied by the development of technology and Internet. Nowadays, digital currency is more common and permeated in all aspects of people's clothing, food and housing. When people explore Internet technology and AI technology, digital currency is also changing at the technological level. The evolution of monetary form is not only the development process of financial industry, but also the requirement of social change to financial industry. From the evolution process, we can clearly recognize the role played by currency as a commodity exchange medium.

\subsection{Motivation of the evolution of digital currency form}

From perspective of the development of money, the biggest cause of the change of money form is the human demand and the development of science and technology. In terms of human demand, the development of society stimulates people's desire for commodity trading. Under this stimulation, the commodity market will ask for currency that is more fast in circulation and suitable for trading conditions. The prosperity of market economy requires increased efficiency of monetary transaction, which is the most basic motive force for the development of monetary form. In this regard, digital currency can meet people's needs at different levels. People's demand for convenient transactions, demand for monetary stability and cross-border demand for money can be all realized by digital currency. From perspective of technology supply, the development of the social technology affects the development of monetary form. With the rapid development of science and technology, people's rapid acceptance and application of technology directly promoted the change of monetary form. In particular, mobile communications and big data have provided strong technical support for digital currency.

\subsection{Actual requirements of the research on the evolution of digital currency}

The emergence of digital currency has adapted to the present situation of the contemporary economic life. It is mainly reflected in three aspects: First, it has greatly satisfied people's demand for currency convenience; the emergence of digital currency on major platforms is conducive to people's familiarity and use of digital currency and enjoy the effect of financial innovation. Second, it is the competition demand of big financial institutions in the era of science and technology. There are many 
digital currencies in the market since there is no issuing standard for digital currency. Third, the emergence of digital currency can deal with the challenges of currency competition from other countries and our own financial security. To speed up the development of digital currency and the setting of security performance enables China to set foothold in the international network system and guarantee the security of domestic currency.

\section{Basic Problems of Digital Currency}

The first problem is the nature of digital currency. Money has commodity attributes and debt attributes. These two attributes will change in different periods and under different conditions, which will tend to be one of them. The digital currency itself is not of value, but a kind of value symbol. It's in essence a monetary symbol and a kind of credit currency. The second problem is about the issuer of digital currency. This involves the issuing body of the digital currency. Historically, the state is the subject of currency issuance, which originates from the theory of currency nationalization. However, government issuance of paper money tends to conflict with the market in the circulation stage of paper money, which may cause economic turmoil. The in-depth controversy of the monetary body is the issue of credit guarantee and the issuer's credit. The credit rating of different issuers can be different, which is also the key of currency risk. The third problem is the quantity control of digital currency, that is, the anchoring principle of the digital currency issue. There are two aspects accounting for this problem. First, the determination of the circulation of the basic currency in the commodity currency stage is based on the stock of the material. In the stage of credit currency, the circulation of digital currency is mainly linked to the development of science and technology, which is a better anchor mechanism for currency issuance. Second, it's about the circulation of digital currency. In addition to the base money, the circulation of digital currency is determined by the ability of credit creation. Credit creation is no longer just the business of the bank. Currently, the securities companies and other financial institutions also have the ability of credit creation along with the development of the financial system. The function of their credit creation affects the monetary multiplier and thus affects macro monetary policy. The development of science and technology has expanded the function of credit creation and changed the credit mechanism of traditional currency, which is also the outcome of the development of digital currency.

\section{Analysis of the Core Mechanism of Digital Currency}

There are two design ideas for the core mechanism of digital currency because of different efficiency and risks. The design process involves two aspects of financial efficiency and risk.

\subsection{Design idea of digital currency}

In recent years, the financial development has presented the trend of Decentration and Financial Disintermediation by the influence of the Internet. Currency non-nationalization theory holds that the guarantee of the effective function of the market mechanism is free competition. "Decentration" is the form of financial relations formed by the efficient transmission of information in the Internet age. The innovation of block chain technology can guarantee the "Decentration" of digital currency. However, there are also some problems in the process of "Decentration", such as market monopoly, risk control, fairness and efficiency, currency stability and so on. The risk and supervision in the process of "Decentration" is also questionable.

The digital currency has also realized the transformation from the tripartite model to the binary model, from the traditional borrowers, the banks and the lender to the two party mode of P2P. The technology innovation of the block chain provided the two technical routes based on account and non account for digital currency. Different countries will consider docking with financial institutions in the design of the digital currency. One is direct docking between the central bank and the customer as well as the direct transaction with customers on the central bank system. The other is that the commercial bank deals with the customers on the system of the central bank, namely, binary structure 
model of the central bank system. The two models are the realistic reflection of the dispute focus in Decentration and Financial Disintermediation.

\subsection{Exploration of the binary credit mechanism}

The transformation of digital currency from the tripartite model to the binary model is based on the change and development of modern technology. Theoretically, the theory of private digital currency is not very mature and the supervision of the market mechanism can hardly provide sufficient conditions for the development of digital currency. The government's intervention in money has blocked digital currency to form a legalized "Decentralization" theory. Therefore, the theoretical basis of both private digital currency and legal digital currency is not yet mature. From the perspective of real development, the credibility of the central bank is relatively high in the process of monetary reform and innovation. Therefore, the issued digital currency has strong legal efficiency. Moreover, it is regulated by the central bank, so as to maintain financial order. The digital bill experiment platform introduced by the People's Bank of China is based on block chain technology, which adopts digital bill as a carrier of digital currency. However, it's actually the trial of Decentration and Financial Disintermediation to realize symmetric information and disintermediation of notes, thus improving the efficiency of the transaction.

\section{Risk Regulation of Digital Currency}

The reform also has the risk while facilitating the financial progress, and the financial supervision is the necessary measure to deal with the financial risks. In shortage of supervision, technical progress will not only be unfavorable to the development of the financial sector, but will increase the financial risk. As a result, the operation of digital currency in the market will be confronted with huge market risks. Such risks are not only the risk of digital currency itself, which will also spread to the entire financial system, thus causing market turmoil. Therefore, it is necessary to strengthen the supervision of the digital currency.

\subsection{Monetary cognition theory}

The recognition of monetary neutrality in classical economics is based on the hypothesis of complete rational man. However, human reason is limited and desire is infinite in reality. Money is not neutral in people's cognition. People will have hallucinations on money and lead to all kinds of monetary effects. People have cognitive bias on risk and the limited understanding of financial knowledge, which makes their financial behavior quite uncertain, thus making it easier to cause financial risks. Under the system of credit money, the credit in the financial field presents great uncertainty and complexity. Excessive or too few credit currencies will cause regulatory risk. Driven by modern technology, digital currency is more flexible and playing increasingly dominant role in the market. It is difficult to effectively estimate the creation ability of digital currency, so it is not that easy to implement regulation.

\subsection{Risk analysis of digital currency}

The risk of digital currency mainly includes credit risk, legal risk, management risk and so on. The risk includes predictable and unpredictable risks, systematic risk and non-systematic risks. These risks shall especially be paid attention to for digital currency. Digital currency depends on the development of Internet. Once the risk can't be timely detected and treated, it will lead to a greater risk in a short time. The maturity of the digital currency and the determination of the legal status are a gradual process. The smooth operation of a currency in the market requires a certain market demand, the support of the policy system and the joint maintenance of the related management and supervision mechanism. The policy system is predictable and adjustable. The characteristics and changes of market shall be captured in time. The most important area of the Internet age is credit regulation. Legal risk calls for the continuous improvement and perfection of the legal system, which shall be constantly improved with the development of society. Managing risk is a joint process of the whole 
financial system and network system, which can be a long-term process.

The digital currency supervision should first be carried out from the source, that is, the digital currency issuer. It is necessary to evaluate the seniority of issuers, the conditions of issuance and the ability of later processing, to allow them to issue digital currency under the condition of ability and condition, so as to supervise issuers' behaviors in real time. When carrying out the regulation of digital currency, it's necessary to adopt a positive regulatory attitude instead of relying solely on the supervision of computer system. That's to say, human supervision and computer system shall be combined to play supervision role, especially in terms of the issuance and market application of digital currency. The regulatory principles of appropriate management and the omni-directional supervision methods before, in and after the event can transform the risk of digital currency to predictable risk as much as possible, so as to establish a regulatory system that is compatible with the economy and coordinated with digital currency on this basis. At the same time, it's imperative to ensure the effective release of digital currency and prevent the spread of digital currency in some platforms.

\subsection{Key mechanism of digital currency supervision}

For the regulation of digital currency, scholars have put forward some opinions and suggestions from the aspects of supervision attitude, methods and principles, but few scholars proposed the key regulatory mechanism. In addition to the technical problems of the digital currency itself, the key and difficulty of supervision is the information asymmetry of the whole process in the operation of the digital currency. The infiltration of science and technology in the financial field makes people and money gradually present a state of integration, that is, the credit personification. Credit personification requires to establish a personified credit monitoring system in the established digital currency system. It is necessary to evaluate and supervise the behavior of the main body in microcosmic sense, supervise the circulation of money and the performance mechanism of the market on the macro level. The establishment of a single-to-multidimensional regulatory system can greatly reduce information asymmetry. At the same time, the personified supervision system can be monitored in real time and adjusted in time. Therefore, the system of three-dimensional credit is the most important part in the risk supervision of digital currency.

\section{Conclusion}

First of all, this paper compares the difference between digital currency and other currencies on the basis of analyzing the evolution process of the currency. Through the effect of social demand and technology supply, this paper analyzes the emergence and result of digital currency, indicating that the key impetus of digital currency reform is the development of financial technology. As a result, it presents the importance of digital currency in terms of financial institutions, social needs and international finance. Secondly, this paper summarizes four mechanisms in the operation of digital currency aiming at the value of money, issuing parties and issuing quantity, which can clearly show the development of digital currency under the technology innovation of block chain. Thirdly, this paper also discusses the transformation of the credit mode of digital currency, from the binary model to the single model, so that the credit system of the currency is more perfect. Finally, according to the risk of digital currency, this paper puts forward effective countermeasures for risk supervision and provides a multi-dimensional credit risk evaluation system to ensure the safe operation of digital currency. No matter for the current digital currency market or the development of digital currency in the future, the operation and supervision shall be carried out based on a clear understanding of digital currency, thus making digital currency handle a butcher's cleaver skillfully in the Internet era.

\section{References}

[1] Stiner M C, Munro N D. On the evolution of diet and landscape during the Upper Paleolithic through Mesolithic at Franchthi Cave (Peloponnese, Greece) [J]. Journal of Human Evolution, 2011, 
60(5):618-636.

[2] Liu H, Lee P P C, Lui J C S. On the credit evolution of credit-based incentive protocols in wireless mesh networks [J]. Computer Networks, 2013, 57(17):3327-3343.

[3] Hora J M, Singer B S, Worner G. Volcano evolution and eruptive flux on the thick crust of the Andean Central Volcanic Zone: 40Ar/39Ar constraints from Volcan Parinacota, Chile[J]. Geological Society of America Bulletin, 2007, 119(3):343-362.

[4] Perucca G, Belforte P, Garetti E, et al. Research on Advanced Switching Techniques for the Evolution to ISDN and Broadband ISDN[J]. IEEE Journal on Selected Areas in Communications, 2003, 5(8):1356-1364.

[5] Wu Y Z, Zhang S N. Evolution of oxygen and nitrogen abundances and nitrogen production mechanism in massive star-forming galaxies [J]. Monthly Notices of the Royal Astronomical Society, 2013, 436(1):934-942.

[6] Staub R B, Souza G D S E, Tabak B M. Evolution of bank efficiency in Brazil: A DEA approach [J]. European Journal of Operational Research, 2010, 202(1):204-213.

[7] Pangga I B, Hanan J, Chakraborty S. Pathogen dynamics in a crop canopy and their evolution under changing climate [J]. Plant Pathology, 2011, 60(1):70-81.

[8] Thomson D, Russell K, Becker L, et al. The evolution of a new publication type: Steps and challenges of producing overviews of reviews [J]. Research Synthesis Methods, 2010, 1(3-4):198. 